\title{
As Iniciativas de Desenvolvimento Local e a Diversidade das suas Orientações ${ }^{1}$
}

\author{
Alcides A. Monteiro *
}

\begin{abstract}
$\mathrm{R}$ (re)conhecido o seu trabalho em prol do desenvolvimento de comunidades locais. As acções protagonizadas falam por si: apoio a grupos sociais desfavorecidos, lançamento de iniciativas de ordem social, económica e cultural, promoção da empregabilidade, incentivo à participação e ao empowerment, acção conjunta com os poderes autárquicos... Menos conhecida é, contudo, a diversidade de orientações sobre as quais se tem fundado um plano de trabalho e de intervenção. $\mathrm{O}$ que as move? Que sentidos dominantes conferem à sua acção? Por que valores e representações pautam as suas escolhas em termos de prioridades para a intervenção?

O presente texto resume algumas das conclusões extraídas de uma pesquisa para Doutoramento, que culminou com a apresentação da tese com o título "Associativismo e novos Laços Sociais: as Iniciativas de Desenvolvimento Local em Portugal". Centra-se, em particular, na apresentação de uma tipologia identificando quatro perfis de IDL's, em função das orientações dominantes da sua aç̧ão: orientaçãa instrumental, orientação parapública, orientação autónoma e solidária, e orientação militante.
\end{abstract}

Palavras-chave: desenvolvimento local; IDL's; associações; tipologia.

\section{IDL's: quem são?}

Das Iniciativas (ou Associações) de Desenvolvimento Local (IDL's ou ADL's ${ }^{2}$ ) é hoje cada vez mais (re)conhecido o seu trabalho em prol do desenvolvimento de comunidades locais: apoio a grupos sociais desfavorecidos, envolvimento em programas nacionais e comunitários virados para a promoção da inserção e coesão sociais, lançamento de iniciativas de ordem social, económica e cultural, promoção da empregabilidade, incentivo à participação e ao empowerment, acção conjunta com os poderes autárquicos...

Contudo, contrariamente a vários outros países em que as organizações ligadas ao desenvolvimento local gozam de uma definição legal própria, no contexto das distintas definições legislativas abrangendo organizações privadas sem fins lucrativos que em Portugal vigoram não é possível encontrar contemplado um enquadramento jurídico específico para as IDL's. Esta denominação não resulta de um regime legal que defina concreta e exactamente o que são e quem são as IDL's, surgindo "empiricamente" sob esta designação entidades com personalidades jurídicas distintas: associações, fundações, cooperativas, misericórdias, entre outras. Com efeito, para a nomeação dos casos concretos identificados como IDL's (matéria de análise neste texto) concorre essencialmente o que poderia denominar-se por reconhecimento interpares, traduzido no dito reconhecimento a uma dada organização, por parte de outros actores próximos e igualmente envolvidos em dinâmicas de desenvolvimento local, da efectiva posse de um currículo relevante e experiência demonstrada na condução de intervenções que assumem as características fundamentais de uma acção em prol do desenvolvimento local:"Afirmam-se como Associações de Desenvolvimento Local (ADL's)

\footnotetext{
* Sociólogo. Professor Auxiliar na Universidade da Beira Interior (UBI). Contacto: alcides.monteiro@yalıo.com

1 Texto que recupera algumas das conclusões apresentadas na tese de doutoramento com o título de "Associativismo e novos Laços Sociais. As iniciativas de Desenvolvimento Local em Portugal", defendida em Julho de 2002 na Universidade da Beira Interior (UBI).

2 Designação igualmente utilizada em muitos dos textos que a estas organizaçōes se reportam.
} 
porque, de um modo geral intervêm na comunidade local ou na região, mobilizam as pessoas e os agentes para intervenções mais alargadas, promovem o estudo das potencialidades e recursos do território, dinamizam iniciativas de carácter económico, social, cultural, ambiental, executam projectos de educação e formação, gerem programas nacionais e europeus" (Brás, 2000).

No segundo "Guia das Iniciativas de Desenvolvimento Local", editado pela rede ANIMAR em 1998, surgiam referenciadas cerca de 400 entidades como possuindo trabalho relevante no domínio do desenvolvimento local. Este e outros documentos ${ }^{3}$ permitem, simultaneamente, reconhecer características essenciais a estas organizações, algumas das quais identificadoras de traços comuns, mas muitas outras alimentando a constatação de que estamos perante um movimento associativo que não é uno, que se compõe de entidades com características e posturas distintas, que o desenvolvimento local se pratica com diferentes graus de aproximação aos princípios básicos que sustentam a sua especificidade.

No que concerne a alguns dados de caracterização mais orgânica destas iniciativas, uma primeira constatação é a de que, se durante muito tempo se associou a ideia de Desenvolvimento Local a uma intervenção privilegiadamente em meio rural, é hoje compreensão corrente que este tipo de limite (até pela própria indefinição geográfica e conceptual das fronteiras entre "rural" e "urbano") já não se estrutura como adequado a confinar os territórios de intervenção das IDL's. Estamos perante um fenómeno que se dissemina de modo regular pela totalidade do país (continente e ilhas), esbatendo até desequilíbrios que lhe são tradicionais, como sejam as diferenças litoral/interior, Norte/Sul e rural/urbano. Apesar de tudo, à semelhança do verificado com outros tipos de associações, é no Norte e no Centro que se concentram mais de metade das entidades inquiridas.

Por outro lado, ressalta a relativa juventude destas organizações, sendo que apenas 8 das 196 IDL's surgiram antes do 25 de Abril. É, pois, na transição entre as décadas de 80 e 90 que se dá o grande incremento na emergência de tais instituições. Como explicação possível, a já avançada em alguns meios segundo a qual existe uma relação entre estes "picos" e contextos particulares favoráveis que decorrem da implementação no nosso país de medidas e programas comunitários com alguma envergadura (ANIMAR, 1998; Serafim, 1999). A implementação em 1990 do $1 .^{\circ}$ Quadro Comunitário de Apoio (1990-1994), o lançamento em 1991 da iniciativa LEADER I (1991-1994), assim como a posterior coincidência temporal na decisão de dar continuidade a estas medidas (1994), respectivamente com o 2. ${ }^{\circ}$ Quadro Comunitário de Apoio (1995-1999) e Iniciativa LEADER II (1994-1999), terão multiplicado não só as oportunidades e apoios disponíveis, como igualmente as solicitações políticas ao crescimento do número de associações envolvidas em processos de desenvolvimento local.

No que se reporta à natureza das entidades fundadoras, o retrato produzido pelos dados disponíveis dá conta de um primeiro impulso com origem na vontade de indivíduos que, em nome próprio, se agruparam no sentido de constituir estas organizações. Uma tendência que se inicia no pós-25 de Abril e se mantém dominante durante a década de oitenta, atestando a efervescência de uma certa vontade de participação cidadã, mobilizada a partir de interesses individuais e em torno de motivações de distintas naturezas, para a formação de colectivos organizados. Só mais tarde, após 1990, é visível, em paralelo, uma maior presença de entidades colectivas na condução dos processos de fundação das IDL's, associadas entre si ou em articulação com pessoas singulares. Característica esta que, em termos regionais, marca mais o Norte do país por contraste a um Sul (Alentejo e Algarve) onde as IDL's constituídas são-no essencialmente pela conjugação de vontades individuais. Independentemente das razões que a fundam, a verdade é que a base associativa tende a modificar-se ao longo do espaço de vida das instituições. Incrementou-se a composição mista dos órgãos sociais das IDL's (de $30,1 \%$ para $25,4 \%$ ), muito por influência da abertura a entidades colectivas por parte de IDL's fundadas por pessoas singulares.

\footnotetext{
${ }_{3}^{3}$ No âmbito da elaboração da tese que serve de base a este texto, foi dada continuidade ao levantamento já iniciado pela ANIMAR. Prolongado o inquérito às iniciativas recenseadas mas que não haviam respondido ao mesmo, foi possível compilar dados de caracterização relativos a 196 IDL's.
} 
No oposto, apenas em quatro situações associações criadas por associados colectivos vieram a admitir associados individuais.

$\mathrm{O}$ que fazem e para quem direccionam a sua acção? Uma análise dos territórios privilegiados de intervenção revela a abrangência de um espaço que se aproxima essencialmente da ideia de "região" ou de "sub-região". Um agrupamento de concelhos em $32,7 \%$ dos casos, e o limite regional em outros $20,9 \%$, são as duas referências territoriais mais comuns para a acção. Sobre os territórios geográficos visados e as populações aí residentes são estabelecidos e concretizados planos de acção onde impera a multiplicidade. Acções de "desenvolvimento económico e social local”, aposta no "emprego e formação", "gestão de estabelecimentos e prestação de serviços sociais", iniciativas de "preservação do ambiente", são algumas das áreas mais privilegiadas por estas IDL's.

Os destinatários/utentes dos serviços prestados pelas IDL's são passíveis de divisão em dois agrupamentos. Por um lado, as "pessoas", por acções que se podem dirigir às populações no seu todo, sem delimitação, ou tomar como alvo subgrupos concretos dessa população. Predominam de modo claro as acções de "hetero-ajuda" sobre as de "auto-ajuda", na medida em que só 9,7\% dos serviços é prestado especificamente em favor de associados da instituição. Como segundo agrupamento de destinatários surgem "instituições" de diferentes tipos, públicas e privadas, com as entidades representantes do mercado e do poder local a serem descritas como destinatários mais comuns.

Finalmente no que concerne aos recursos disponíveis, duas notas breves de caracterização. Em termos de recursos humanos, como seria de esperar, trata-se de organizações de pequena dimensão, 62,7\% a não ultrapassarem os 10 quadros (dirigentes, técnicos, administrativos e outros $^{4}$ ). Apenas 6 IDL's possuem um quadro de recursos humanos superior a 50 pessoas. Quanto aos recursos financeiros disponíveis para a gestão das IDL's, por comparação a alguns dados internacionais, os números referentes ao universo das IDL's portuguesas revelam um peso significativo da rubrica respeitante ao financiamento estatal sobre o total das receitas destas organizações. Em termos médios, 66,9\% dos recursos têm essa origem, enquanto que $29,2 \%$ resultam da prestação de serviços, vendas, contribuições dos utentes, quotizações e outras vias de obtenção de receitas próprias, e apenas 3,9\% têm origem em donativos voluntários. Verifica-se nestas percentagens uma quase inversão da repartição assinalada, por exemplo, em França para idêntico sector.

\section{O que as move?}

Se no plano das características orgânicas são visíveis distinções que denunciam a variedade de composições associativas que marcam o universo das IDL's, mais complexo e diverso é o plano das suas orientações programáticas, a partir do qual derivam formas de condução da intervenção social.

Algumas têm sido as tentativas de interpretar esta diversidade. Os avanços já empreendidos desaguam não só em propostas de caracterização do sector como, nalguns casos, em procedimentos classificatórios ou quasi-tipologias que procuram essencialmente propor dimensões em torno das quais é possível identificar tendências de sinal distinto (Neves, 1995; Esdime, 1997; Cristóvão, 1999; Portela, 1999). Entre essas dimensões, salienta-se como mais significativa e comum a dicotomia fundada sobre a "base social" das diferentes IDL's, distinguindo entre as que resultam de empenhamentos única ou essencialmente individuais e cuja sua base são, assim, os cidadãos, e aquelas que têm como ponto de partida uma vontade institucional e como base fundadora entidades colectivas públicas e/ou privadas, sem olvidar circunstâncias em que se podem conjugar estas duas dinâmicas. "Enquanto as primeiras correspondem, maioritariamente, a processos de cidadania activa através da participação em contextos de desenvolvimento, as segundas decorrem, principalmente, de processos de estabelecimento de parcerias necessárias a candidaturas a programas comunitários" (Neves, 1995: 46) As primeiras, designa-as José Portela de "militantes", as segundas de "institucionais" (Portela, 1999: 57), numa distinção igualmente

${ }_{4}^{4}$ Estagiários, formadores, animadores, consultores, pessoal auxiliar, etc. 
reconhecida por Debbasch e Bourdon para o caso francês (1993: 32) e que os autores denominam, em correspondência, de "administrativas" e "tradicionais". Contudo, mais importante que diferentes designações, são os aparentes reflexos desta distinta base social sobre a condução da intervenção e a hierarquia de princípios que orientam as IDL's, sem que, em boa verdade, as análises produzidas sejam verdadeiramente explícitas quanto ao seu alcance.

Precisamente porque se julga importante valorizar uma melhor compreensão destas iniciativas associadas ao desenvolvimento local não apenas a partir de factores de configuração (base social, modo de funcionamento, domínios de actividade, perfil de dirigentes e técnicos ou fórmulas de financiamento), a análise que aqui se desenvolve debruça-se sobre as orientações que sustentam e justificam estratégias de intervenção adoptadas, no trânsito entre princípios e acção. Uma apreciação comparativa dos discursos veiculados por representantes das IDL's s ${ }^{5} \mathrm{em}$ torno de categorias que marcam planos fundamentais na orientação e acção das mesmas, permitiu identificar agrupamentos de atributos (e respectivas propriedades) que se correlacionam e reforçam mutuamente de modo mais intenso em torno de quatro grandes perfis de IDL's: iniciativas de “orientação instrumental", iniciativas de "orientação parapública" iniciativas de "orientação autónoma e solidária" e iniciativas de "orientação militante".
Um primeiro perfil de Iniciativas de Desenvolvimento Local toma como designação possível o de associações de "orientação instrumental", dado assumirem como central ao seu esforço de intervenção uma maximização das competências técnicas e sociais, em detrimento da afirmação de um projecto político e ideológico autónomo. Criadas para dar resposta a problemas sociais concretos, prolongar e consolidar institucionalmente acções já iniciadas ou apoiar a acção dos municípios no campo da luta contra a pobreza e exclusão social, os seus objectivos incidem essencialmente sobre a vertente instrumental do desempenho da IDL, visíveis na preocupação em sustentar, alargar ou enriquecer uma estrutura orgânica e de gestão que permita o exercício de uma intervenção mais eficiente e eficaz. Simultaneamente, torna-se a via de afirmação do seu carácter distintivo face a uma intervenção do Estado, tomada como mais burocrática, menos flexível, menos capaz de interpretar as reais necessidades das comunidades e mobilizar recursos locais num esforço multidimensional. Por outro lado, o prosseguimento desta estratégia leva a que estas IDL's sejam em muitas circunstância mais solícitas perante as oportunidades que o mercado oferece, aproveitando a exploração de nichos de mercado e actividades com carácter inovador (nomeadamente serviços de proximidade) como expansão da sua acção e fonte de rendimentos adicionais.

"Trabalho realizado junto de 22 casos a partir de entrevistas a técnicos mandatados em representação das IDL's, a que se somaram os dados já obtidos por inquérito e documentação escrita disponibilizada pelas respectivas organizações. Ainda que tomando como ponto de partida situações concretas, qualquer um dos perfis identificados não corresponde directamente a nenhum caso específico, havendo sim uma aproximação possível e maior identificação de cada associação com um dos perfis recenseados, por simultânea exclusão em relação a outros perfis. 
Figura 1 - Orientação instrumental

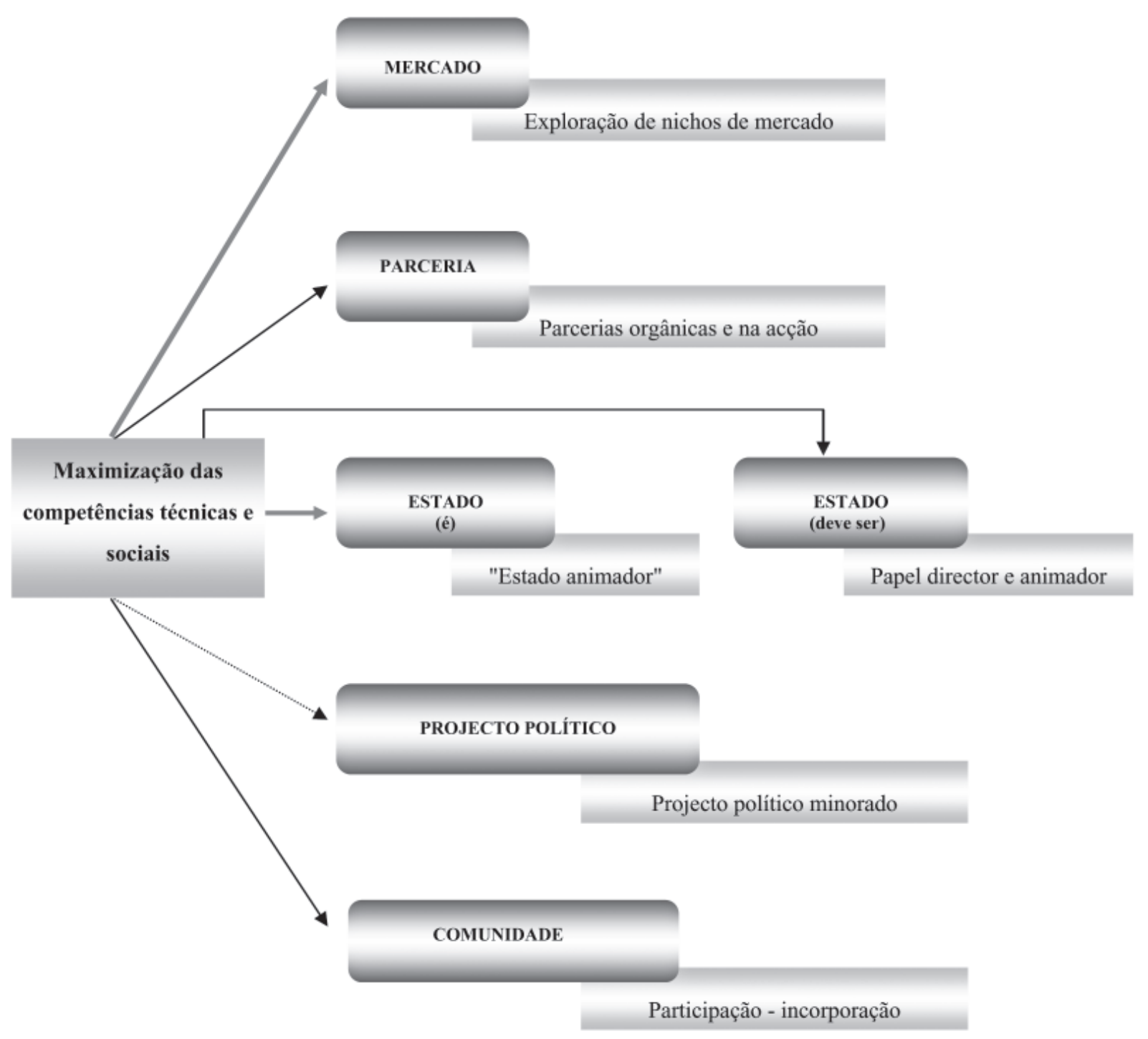

Do Estado, por sua vez, mantêm o reconhecimento deste como o garante regulador da solidariedade social que, numa posição desejável de "Estado animador", assuma responsabilidades no financiamento das acções empreendidas ao mesmo tempo que dá continuidade às funções de produzir directivas, animar e desenvolver parcerias com estas iniciativas. Nessas parcerias, estas IDL's identificam-se como mais um dos protagonistas de uma intervenção multidimensional e multisectorial sobre o desenvolvimento local, admitindo continuar a caber aos poderes públicos um papel director na determinação das linhas orientadoras da intervenção e às associações o de serem "lideres e executores locais", segundo um compromisso de articulação que desejam que o Estado assuma. Por sua vez, esta posição perante as parcerias reflecte-se "para baixo", ao pautarem as suas relações com as comunidades e populações aí residentes por regras semelhantes de colaboração. Ao mesmo tempo que procuram reforçar os patamares de mediação entre populações e instituições, desenvolvem predominantemente com os grupos sociais relações de participação-incorporação, no sentido de auscultação, incentivo à acção e seu envolvimento directo nas acções empreendidas, mas pela instituição delineadas. Todos estes processos se pautam pela ausência de uma orientação política expressa, ou em alternativa por um projecto político minorado, que resulta directamente da aceitação do Estado enquanto instância reguladora, em paralelo com uma recusa 
de compromissos políticos e ideológicos que comprometam a equidistância e neutralidade de uma intervenção que se pretende acima de tudo apostada na alternativa pelo prisma do "fazer mais e melhor".

O seguinte perfil, o de uma "orientação parapública" assume com o anterior várias afinidades, desde logo por idêntica ausência de um projecto político interno e autónomo. Contudo, algumas dimensões específicas justificam tal distinção. E a primeira delas resulta das motivações que presidem à constituição das iniciativas, onde o enquadramento na estruturação orgânica do poder local (Associações de Municípios) ou a solicitação por parte do Estado e/ou candidatura a programas nacionais ou comunitários (por exemplo, LEADER ou IQADE) pesam sobre a arquitectura e objectivos à partida delineados. Por um lado, ao nível da sua fundação, marca-se a diferença pelo facto de a base societária destas iniciativas ser (quase) exclusivamente composta por instituições e, nestas, por uma maioria oriunda da administração central e local. Quanto aos objectivos, onde domina uma visão mais estrutural / funcional do desenvolvimento local, em causa não está a procura de alternativas ao exercício de uma função de regulação social assumida em exclusivo pelo Estado, mas uma função que se desenha no prolongamento para a acção das orientações programáticas pelos poderes públicos delineadas, e daí a atribuição por muitos autores do epíteto de "auxiliares da administração". Com esses representantes do poder público central, mas igualmente com o poder local, agentes económicos e agentes culturais, as parcerias estabelecidas resultam muitas das vezes de exigências definidas pelos programas a executar, modelizando-se de forma orgânica com o propósito de criar estruturas (conselhos, assembleias, corpos directivos) que posteriormente sustentam a acção. Ao contrário, e distintamente da própria orientação instrumental, nota-se uma desvalorização dos princípios de comunidade e de participação, em nome de objectivos mais estruturais e de parcerias estratégicas e instrumentais. A ausência de um projecto político construído em autonomia é simultaneamente consequência das motivações e objectivos na base da constituição das iniciativas, mas também causa de um apagamento da dimensão política da acção em favor de uma conformidade e de um exercício essencialmente técnico e de gestão. 
Figura 2 - Orientação parapública

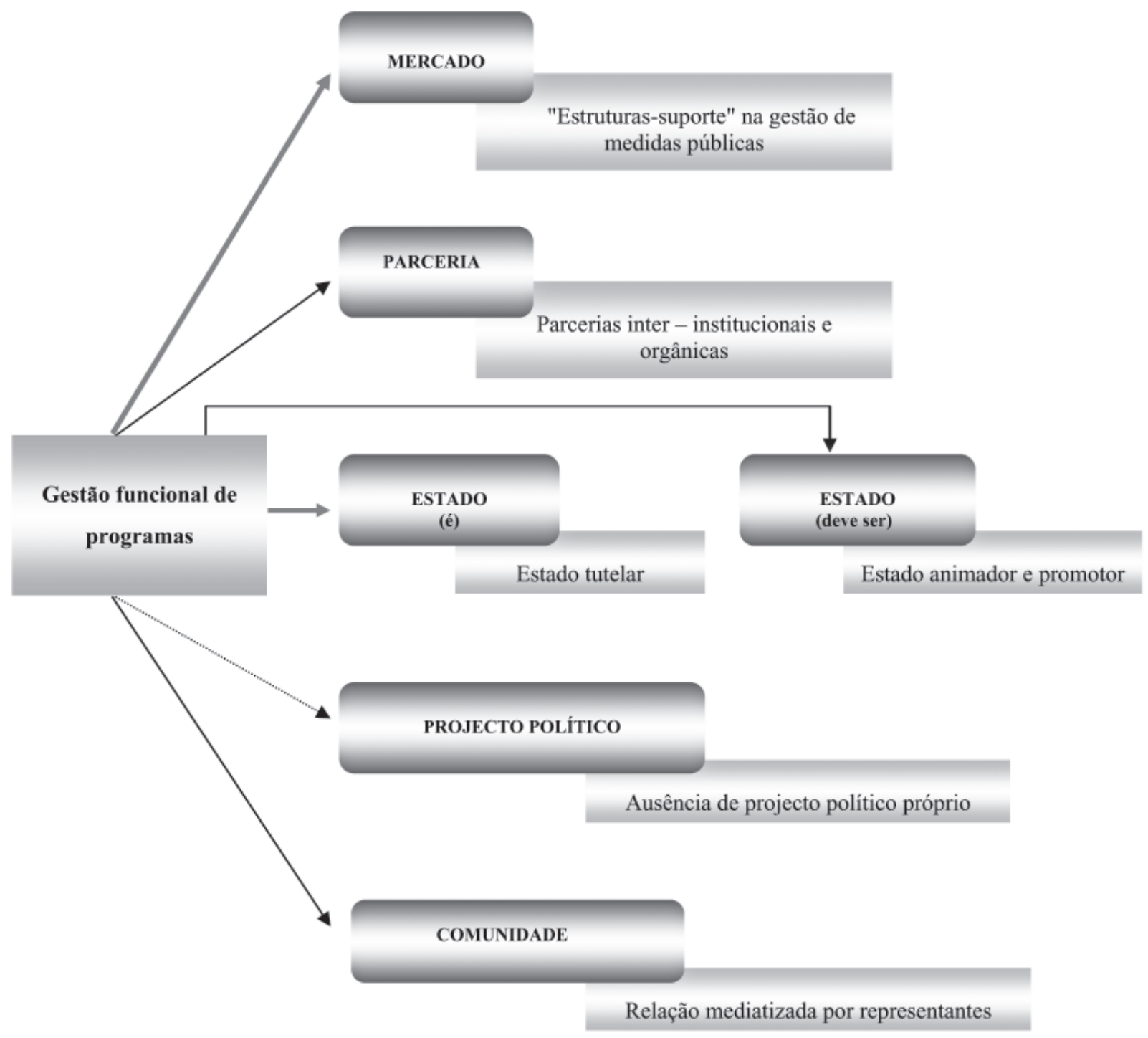

Precisamente porque a afirmação de um projecto político próprio se estabelece como primeira das prioridades, torna-se possível aproximar os discursos de um conjunto de iniciativas a uma "orientação autónoma e solidária" que conduzirá a sua intervenção, pautada por rumos distintos dos apresentados para os perfis anteriores e onde a discussão sobre os valores e princípios próprios de uma ideia alternativa de desenvolvimento local se assumem como influência mais presente e pertinente. Advogar e reclamar um exercício mais democrático, solidário e aberto sobre a intervenção social no combate à exclusão social e promoção de dinâmicas de desenvolvimento local, surge como uma constante que determina vários campos de decisão. 
Figura 3 - Orientação autónoma e solidária

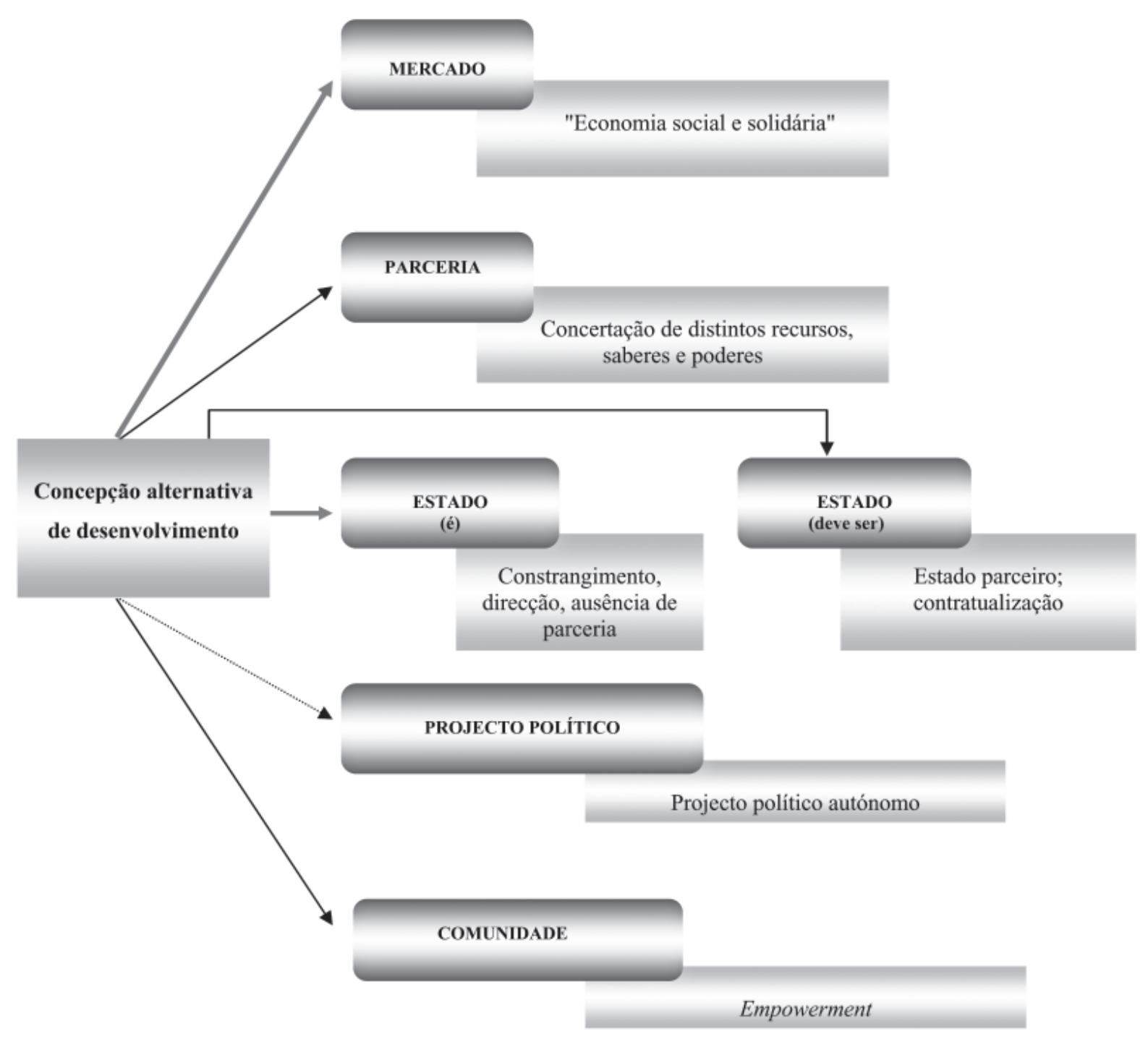

Na sequência desse compromisso, a posição actualmente assumida por um Estado que, entre a tutela e a animação, incentiva à implicação na execução das políticas públicas mas não abre espaços a uma colaboração e concertação de esforços na definição dos objectivos e orientações políticas que lhes dão origem, é interpretada pelas iniciativas que se aproximam deste perfil como sendo de constrangimento, excessiva direcção ou ausência de parceria. Reclama-se, em contrapartida, uma outra postura que passe por um Estado verdadeiramente parceiro e por um compromisso de articulação onde a função mediadora das associações na reactualização dos laços sociais e o seu papel numa regulação social solidária sejam verdadeiramente reconhecidos. Para algumas iniciativas, essa via poderá ser viabilizada por uma fórmula de contratualização.
Por outro lado, a presença de um debate aberto sobre as finalidades e orientações aparece igualmente associado à determinação das estratégias de intervenção, desde logo numa condução hetero-centrada da formulação dos objectivos a prosseguir, pretendendo conferir voz às comunidades, suas necessidades e solicitações. Nesse e em outros momentos da intervenção, assumem-se as populações e a sua voz crítica como um recurso a incentivar e a promover por forma a produzir um empowerment e consequente autonomização das próprias comunidades. Pretende-se igualmente estabelecer esse debate ao nível das parcerias, conduzidas essencialmente em função da acção concreta e para a qual se crê importante uma lógica de sinergias baseadas em recursos, 
saberes e poderes distintos. Retomando a ideia da construção de um projecto político autónomo, marca ainda este perfil uma convicção de que se estão a construir lógicas (ou métodos) alternativas de intervenção, não em oposição mas em concertação com outras opções e vias seguidas por outros actores.

O quarto e último perfil constatado, o de uma "orientação militante" na condução da intervenção de algumas IDL's, singulariza-se no interior do campo associativo na medida em que remete para os modelos sindicais e dos movimentos sociais dos anos 60 e 70, ainda que seja admissível uma tendência a tornar-se residual e a sofrer significativas alterações na sua formatação, dado os novos contextos em que o associativismo se pretende afirmar não favorecerem esta orientação. De qualquer modo, são ainda visíveis em algumas iniciativas traços fundamentais de um empenhamento mais militante, presentes na força que o "nós"6 ainda adquire na condução da sua intervenção. A própria motivação que preside à sua constituição, assim como objectivos fundamentais, assumem uma orientação auto-centrada no sentido em que a associação pretende ser resposta às necessidades e problemas específicos de um determinado grupo social, que simultaneamente constitui o essencial da sua base societária de fundação, e para o qual se orienta o enriquecimento dos recursos disponíveis que possibilitam a maximização dessa capacidade de resposta.

Figura 4 - Orientação militante

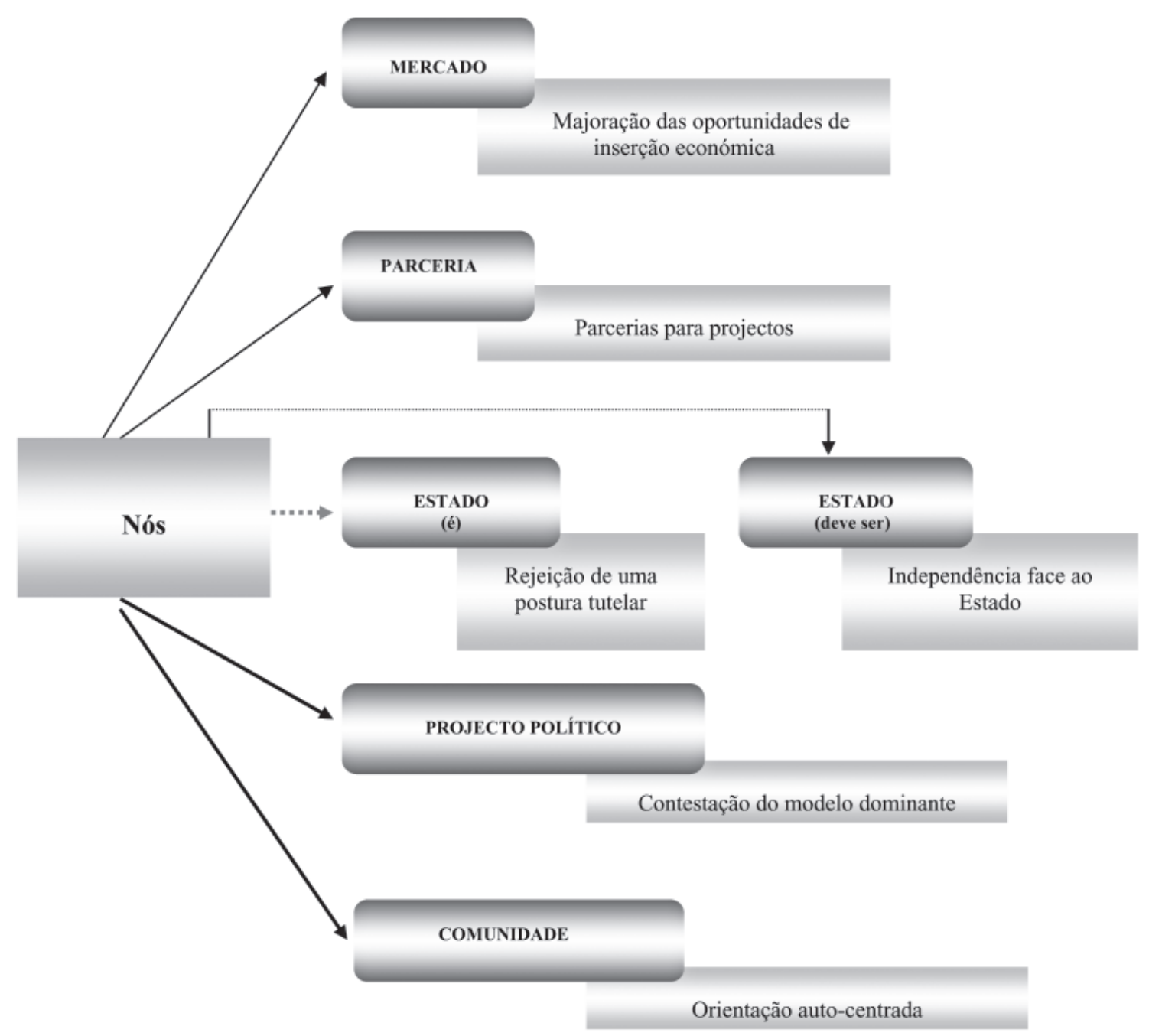

\footnotetext{
${ }^{6}$ De notar ainda que, em todas as iniciativas abordadas que se podem aproximar deste perfil, se constatou que os seus dirigentes são identificáveis com o que Jacques Ion define como a figura do militante: "a sua legitimidade advém-lhe da sua posição no cruzamento de dois conjuntos, o da comunidade e o da sociedade. Ele deve ser originário do mesmo meio dos que deve representar e não pode ser porta-voz senão quando apresenta as características do grupo de pertença. Mas simultaneamente, ele não pode ser guia senão porque participa para além disso de uma rede bem mais larga, essencialmente vertical, que faz aceder o primeiro conjunto a um destino de uma outra ordem" (1997:30).
} 
Como prioridade de acção, a majoração das oportunidades de empregabilidade e de inserção na esfera económica dos grupos sociais que representam, ou uma combinatória destas com medidas de inserção educativa, social e relacional. Contudo, distintamente de uma orientação mais instrumental, a condução da acção pauta-se por um projecto político próprio onde assumem centralidade princípios como os da solidariedade, democracia e autonomia (ideológica e de gestão). Não surpreende, assim, a incidência sobre a procura de uma independência financeira e a rejeição, por vezes mesmo em oposição, de uma postura tutelar por parte do Estado sobre a condução da sua intervenção. É segundo os mesmos princípios que procuram estas iniciativas valorizar e enriquecer uma relação simbiótica e de pertença com os grupos para os quais dirigem a sua intervenção, através de uma participação efectiva dos associados na vida da respectiva associação. No questionamento das formas de regulação dominantes (regulação salarial, regulação social), os discursos de tensão são mais visíveis do que nas iniciativas próximas de uma orientação autónoma e solidária, oscilando entre uma contestação ao modelo dominante, que porventura decorre da tradição de luta dos movimento sociais e sindicais, e a abertura a mecanismos de parceria e negociação com o Estado.

\section{Nota final}

Entre outras dimensões que esta tipologia torna possível explorar, é possível destacar o modo como aponta para a ambivalência como uma das características próprias e mais marcantes do universo do associativismo de desenvolvimento local em Portugal. Uma ambivalência que, ao contrário de alguns discursos referenciando mudanças de sentido dominante no seio do movimento associativo (em direcção a uma crescente dependência face ao Estado ou ao reforço da autonomia de pensamento e acção), impele mais a uma análise do fenómeno que tome como referência central a polaridade de alternativas marcando escolhas fundamentais no seio de cada iniciativa. Polaridades essas que, por sua vez, parecem estruturar-se em torno de três nós determinantes: nas relações com o Estado, nas relações com as comunidades e no modo como se estrutura (ou não) um projecto político próprio.

Sinteticamente, se do discurso associativo ainda não desapareceu a convicção militante quanto ao imperativo de independência face ao Estado, cada vez mais essa orientação é substituída por discursos de concertação. Em certos casos traduz-se na aceitação de uma "autonomia tutelada", no contexto da qual competirá ao poder público regulador definir orientações políticas e programáticas, sendo das IDL's a competência de gerir eficazmente a planificação e execução locais. Para outra iniciativas, tal concertação passará necessariamente pela garantia do carácter autónomo e alternativo da intervenção associativa e pela partilha, em parceria, da capacidade de decisão quanto a formas mais solidárias de regulação social.

Por sua vez, o modo como dicotomiza a concepção da relação com o Estado tem prolongamento nos modelos orientativos das relações com as comunidades de referência. A análise de alguns casos permitiu constatar um nexo de relação entre uma orientação técnico-instrumental na relação com o Estado regulador e tutelar, e o predomínio na relação com as populações, de acções de direcção, gestão e animação. A figura do "Estado-animador" prolonga-se na de "Iniciativa-animadora" que privilegia relações de participação-incorporação com as populações. De igual modo, as organizações que privilegiam um trabalho de parceria com as comunidades e de envolvimento das mesmas nas decisões sobre o seu futuro, uma participação-crítica, reclama dos órgãos públicos idêntico tratamento. Mais ainda, muitas buscam no trabalho com as populações a legitimação de valores e princípios de acção, que posteriormente fundam o desafio ao seu reconhecimento por parte dos poderes públicos.

Finalmente, merece particular atenção uma outra clivagem fundamental, a que recai sobre a existência ou não de um projecto político autónomo. Os dados colhidos indiciam que as polarizações observadas não revelam apenas opções instrumentais distintas (a opção por um ou outro tipo de intervenção, por um ou outro tipo de relação instrumental), mas, acima de tudo, são a expressão ou não de um projecto político forte e autónomo que orienta essas decisões.

Naturalmente, a não expressão (ou mesmo negação) quanto à defesa de uma particular orien- 
tação política não pode ser interpretada como a sua pura e simples ausência. Tende, sim, a marcar um discurso de conformidade que se pauta pela genérica adopção do programa do Estado ou na retracção do projecto político às suas consequências mais modestas, em nome de novas prioridades que passam por acção concreta e competência técnico-instrumental. Convirá neste ponto relembrar a tese de Martine Barthélemy (2000), segundo a qual este apagamento da dimensão do político funda uma das novas fragilidades do mundo associativo.

Mas, novamente, a análise dos casos concretos permite indiciar que o sentido das tendências não seja universal. A crítica das normas, a interrogação sobre o seu sentido, um questionamento das formas de regulação dominantes, a proposta de configurações alternativas na instauração de uma regulação solidária da intervenção social, a exigência de reconhecimento por parte dos órgãos públicos quanto à legitimidade destas opções, são temas que fazem parte do discurso de um significativo corpo de Iniciativas de Desenvolvimento Local.

Em suma, no contraste da opção por uma "lógica de programa", funda-se a opção por uma "lógica de projecto". Fica por identificar o peso estatístico de cada uma das opções.

\section{Bibliografia}

ANIMAR, 1998, Guia das Iniciativas de Desenvolvimento Local, Oliveira do Bairro, Animar.

BARTHELEMY, M., 2000, Associations: un nouvel âge de la participation?, Paris, Presses de Sciences Po.

BRÁS, J., 2000, Novos Objectivos, Métodos e Instrumentos... Um futuro para as ADLs..., Oliveira do Bairro, Solidários (não publicado).

DEBBASCH, Charles et BOURDON, Jacques, 1993, Les Associations, Paris, PUF, Coll. que sais-je?, 4. ${ }^{\mathrm{a}}$ édition.

CRISTÓVÃO, A., 1999, Desenvolvimento: Perplexidades, Propostas e Interrogações, Comunicação ao Seminário "Desenvolvimento Rural e Cooperação Ibero-Americana", Évora, 14 e 15 de Junho de 1999 (policopiado).

EME, B., 2001, "Les associations ou les tourments de l'ambivalence", in Jean-Louis LAVILLE et al, Association, démocratie et société civile, Paris, la Découverte / M.A.U.S.S./ /CRIDA, pp. 27-58.
ESDIME, 1997, Desenvolver Desenvolvendo - Práticas e Pistas para o Desenvolvimento Local no Alentejo, Messejana, Esdime.

ION, J., 1997, La fin des Militants?, Paris, Les Editions Ouvrières.

MONTEIRO, A., 2002, Associativismo e Novos Laços Sociais - As iniciativas de desenvolvimento local em Portugal, Covilhã, UBI.

MONTEIRO, A. e SIMÕES, M. J., 1998, "Novos actores na participação para o desenvolvimento", Revista de Estudios Económicos y Empresariales, Universidad de Extremadura, n. ${ }^{\circ} 11,1998$, pp. 27-42.

NEVES, J. C. C. F., 1995, Iniciativas de Desenvolvimento Local em Portugal, Dissertação de Mestrado em Geografia Humana e Planeamento Regional e Local apresentada à Faculdade de Letras da Universidade de Lisboa (policopiado).

PORTEL A, J.,1999, “O Meio Rural em Portugal: entre o ontem e o amanhã”, Trabalhos de Antropologia e Etnologia, Vol. XXXIX, Fascs. 1-2, pp. 45-65. 